\title{
Chemical Purity and Toxicology of Pigments Used in Tattoo Inks
}

\author{
Henrik Petersen • Dirk Lewe \\ MT.DERM GmbH, Berlin, Germany
}

\section{Abstract}

The safety of tattoo inks has obviously increased in Europe since the existence of European Union Resolution ResAP(2008)1, which resulted in the improved quality control of pigment raw materials due to the definition of impurity limits that manufacturers can refer to. High-performance pigments are mostly used in tattoo inks, and these pigments are supposed to be chemically inert and offer high light fastness and low migration in solvents. However, these pigments were not developed or produced for applications involving long-term stay in the dermis or contact with bodily fluids. Therefore, these pigments often do not comply with the purity limits of the resolution; however, it is required that every distributed tattoo ink does not contain aromatic amines and not exceed the limits of heavy metals or polycyclic aromatic hydrocarbons. Current toxicity studies of pigments underline that no ecotoxicological threat to human health or to the environment should be expected. However, the pigment as well as its impurities and coating materials must be considered. In order to evaluate the safety of pigments according to their impurities, two different validated sample preparation methods are necessary: (1) simulation of their long-term stay in the bodily fluid of the dermis and (2) simulation of cleavage due to laser removal
\end{abstract}

or ultraviolet exposure. The development of standardized, validated and well-adapted methods for this application has to be part of prospective efforts. Concerning legislation, it might be appropriate that the first regulative approaches be based on those of cosmetics.

(C) 2015 S. Karger AG, Basel

\section{Introduction}

Tattooing of humans has a long history and was independently developed in different areas of the world. In the early beginning, tattooing was often used for spiritual signs or for martial reasons, but currently, it is used more as body art to create individual appearance or to demonstrate the belonging to specific groups. In Germany, $10 \%$ of the population is tattooed, and because of its rising popularity, it can be expected that this number will increase within the next years. The results of surveys of a group of tattooed people pointed out that $67.5 \%$ of the people suffered skin problems like itching, burning or redness and that $6.6 \%$ reported persistent symptoms, skin papules or granuloma [1]. During studies on a red pigment, it was 
shown that up to $9.42 \mathrm{mg} / \mathrm{cm}^{2}$ of pigment, 2.53 $\mathrm{mg} / \mathrm{cm}^{2}$ on average, is applied into the skin, depending on the technique and experience of the tattooist $[2,3]$. In the early stages, people dispersed carbon black from campfires or pigments from other natural sources into water in order to get a pigment paste. With industrialization in the 19th century, companies started to synthesize pigments and to produce tons of raw materials to be used by the growing industries for applications like automotive coatings and interior or exterior paints. The development of new pigments for the special demands of several industrial applications is the reason for the current presence of a huge variety of different chemical structures and modifications. Therefore, pigment manufacturers sometimes offer the same pigment class for more than one application (plastics, coatings, printing, textiles). Some pigments that are in accordance with the European Union (EU) Regulation on cosmetics are also available. However because the tattoo business is small and not profitable compared to other industries, like cosmetics or industrial coatings, the pigment manufacturer doesn't make any efforts to develop and produce any specific pigments for this application. Obviously, these pigments often do not comply with the purity limits for heavy metals, harmful aromatic amines and others that are prescribed in the EU resolution ResAP(2008)1 on tattoo inks because the pigments are produced for other applications, where higher limits are tolerated. This is why tattoo ink manufacturers have to carefully choose their supplier and conduct accurate and repeating quality control on the purchased pigments. Authorities' interests in the safety of tattoo inks have increased in the past few years, and there are ongoing discussions about how the safety of pigments can be accurately evaluated. This article will give an overview about the pigments used in tattoo inks and the problems that manufacturers are facing because of the impurities and regulatory situation. This article will also give insight into quality control from the manufacturer's point of view.

\section{Overview of Used Pigments}

The selection of pigments in tattoo or permanent make-up (PMU) ink can differ because of the demand for more natural colors in PMU, but for more bright and shiny colors for tattoo inks. Generally, pigments in water-based inks have to offer high light fastness and stability against bleeding due to the permanent stay of the inks in the dermis because migration of particles in the skin or ultraviolet-induced cleavage of pigments has to be avoided. In table 1, a list of pigments that are often used in tattoo and PMU inks is shown.

Mostly, the pigments belong to the group of high performance pigments, which are supposed to be chemically inert and are distinguished with high light fastness, weather stability and low-migration properties in solvents. These properties make these pigments adequate for tattoo inks because they achieve long-lasting colors in the skin.

\section{Current Regulatory Situation in the European Union}

The first EU Resolution ResAP(2003)2 dealing with tattoo and PMU products was launched in 2003 and was replaced by the actual EU Resolution ResAP(2008) 1 in 2008. Resolution ResAP(2008)1 is the most detailed regulatory document to point out requirements and criteria for the safety of tattoos and PMU. This resolution is a recommendation and has to be transferred into local law, but up to now, just a few EU countries have done so. All other countries do not entirely or adequately regulate this kind of application or the used products. Manufacturers should be encouraged to make data like the composition and the toxicological data of the substances of their product available to the competent authorities [4]. This resolution also lists the aromatic amines that should not be present in tattoos and PMU products because of their potentially harmful carcinogenic, mutagenic, reprotoxic and sensitizing properties. Some examples of 
Table 1. A choice of pigments in tattoo and PMU inks [11]

\begin{tabular}{llcll}
\hline Color & Name & C.I. & Chemical class & Industrial applications \\
\hline & Pigment Blue 15 & 74160 & Phthalocyanine & printing, plastics, textiles \\
Pigment Green 36 & 74265 & Phthalocyanine & automotive coatings \\
Pigment Red 177 & 65300 & Anthraquinone & plastics, automotive coatings \\
Pigment Red 202 & 73907 & Chinacridone & coatings, printing \\
Pigment Red 254 & 56110 & Diketopyrrolopyrrole & automotive coatings \\
Pigment Red 22 & 12315 & Naphthol AS & printing, textiles \\
Pigment Red 210 & 12477 & Naphthol AS & printing \\
Pigment Red 101 & 77491 & Iron oxide $\left(\mathrm{Fe}_{2} \mathrm{O}_{3}\right)$ & food, cosmetics \\
Pigment Orange 73 & 561170 & Diketopyrrolopyrrole & coatings \\
Pigment Orange 13 & 21110 & Diazopyrazolone & plastics \\
Pigment Yellow 138 & 56300 & Chinophthalone & coatings, plastics \\
Pigment Yellow 42 & 77492 & Iron oxide (FeO $(\mathrm{OH}))$ & food, cosmetics \\
Pigment Yellow 65 & 11740 & Single Azo Yellow & coatings \\
Pigment Yellow 55 & 21096 & Double Azo Yellow & printing \\
Pigment Violet 37 & 51345 & Dioxazine & printing, coating \\
Pigment Violet 12 & 58050 & Anthraquinone & coatings \\
Pigment Black 7 & 77266 & Carbon Black & plastics, coatings, cosmetics \\
Pigment Black 11 & 77499 & Iron oxide $\left(F e_{3} \mathrm{O}_{4}\right)$ & food, cosmetics \\
Pigment White 6 & 77891 & Titanium Dioxide & cosmetics, coatings \\
\hline
\end{tabular}

Table 2. Overview of the limits and methods for detection according to ResAP(2008)1

\begin{tabular}{|c|c|c|}
\hline Element or compound & Limit, ppm & Detection method \\
\hline Aromatic amines & absence & $\begin{array}{l}\text { eGC-MS/LC-MS after extraction } \\
\text { in phosphate buffer or } \mathrm{HCl}[4]\end{array}$ \\
\hline $\mathrm{PAH}$ & 0.5 & no method described \\
\hline Benzene-a-pyrene & 5 & no method described \\
\hline $\mathrm{As}, \mathrm{Se}, \mathrm{Sb}, \mathrm{Pb}$ & 2 & no method described \\
\hline $\mathrm{Ba}, \mathrm{Sn}, \mathrm{Zn}$ & 50 & no method described \\
\hline Co, Cu (soluble) & 25 & no method described \\
\hline $\mathrm{Cd}, \mathrm{Cr}(\mathrm{IV}), \mathrm{Hg}$ & 0.2 & no method described \\
\hline $\mathrm{Ni}$ & as low as technically achievable & no method described \\
\hline
\end{tabular}

aromatic amines that are not allowed in tattoo and PMU products are benzidine, 4-chloroaniline, 6-methoxy-m-toluidine or 2-naphthylamine. In addition, a negative list, or list of forbidden colorants, is also included in this resolution. The limit for polycyclic aromatic hydrocarbons (PAHs) is set at $0.5 \mathrm{ppm}$, and the limit for benzene-a-pyrene is $5 \mathrm{ppb}$. Table 2 shows an overview of the limits for aromatic amines, PAHs and heavy metals.
Table 2 also shows that the current resolution is obviously still not sufficient to accurately maintain the toxicological safety of pigments in tattoo and PMU products. For nickel, no specific limits exist, and it is not clear what 'technically achievable limit' really means. Furthermore, an analysis method has only been suggested for the detection of aromatic amines. For PAHs or heavy metals, how to analyze the pigments, so that their safety 
can be evaluated correctly, has not been recommended, yet. Confusion and misunderstandings between manufacturers and authorities happens, if both are analyzing the products in different ways, because this leads to different results which cannot be compared. In the future, it will be necessary to harmonize the analytical methods for tattoo and PMU products and their related limits; otherwise, it will be impossible for manufacturers to perform and maintain suitable quality controls.

\section{Impurities and Toxicological Aspects}

Recent toxicological analysis of high performance pigments found that there is no expected ecotoxicological threat to human health and the environment [5]. These pigments are usually inert and insoluble, which results in minimal ecotoxicological properties. However, the permanent contact of the pigments with human cells or their effects on cells due to cleavage were never considered in any study. Therefore, the several toxicological assessments that have been performed on pigments don't reflect the real environment that they are placed in and are not sufficient to evaluate the toxicological properties of the pigments for longterm stay in the skin. Actually, nearly every existing legislation have referred to the use of possible ingredients in cosmetics; however, none of the substances are intended to be implanted into the skin, especially for years or decades. Furthermore, none of the substances are intended to be spread systemically, as it is known that pigments not only remain in the area where the tattoo has been applied, but are also transported to nearby lymph nodes [6] through the lymphatic system. Therefore, pigments can remain in the region of the tattoo or may travel relatively long distances through our body, as shown in a study published in 2009 [7]. This is why pigment manufacturers have to minimize or remove all unwelcome impurities or by-products in pigments [5]. It was reported that carbon black ink can contain up to $716.94 \mu \mathrm{g} / \mathrm{g}$ of harmful impurities like benzophenone, hexamethylenetetramine or hexachlorobutadiene, which are known to be genotoxic and carcinogenic [8]. These impurities were found after extraction with benzene/acetone using gas chromatography-mass spectrometry analysis. This shows that these compounds can adsorb onto the carbon black pigment surface and can't be determined if the extraction is carried out in a hydrophilic medium [8]. Carbon black is not suspected to cause allergic or irritant skin reactions, but reported cases of tattoos with black ink can potentially be connected to these impurities [1]. Whether the reported toxicological reactions are caused by the pigment itself or by side products has to be investigated. Common cytotoxicity tests analyze extracts and are therefore not suitable for insoluble particles. There is currently no available alternative, validated method to determine the harmful effects caused by applied pigments. Solubilizing pigment particles is also an arguable way to analyze pigments because this would transform an inert and nonbioavailable substance into a bioavailable dyestuff, but this does not represent the reality and can produce 'false-positive' test results [5]. It is mandatory that a standardized and validated method for the safety assessment of tattoo pigments will be available to evaluate the cytotoxicity of pigments according to their long-term stay in the dermis. Heavy metal impurities are often found, especially in inorganic pigments. Jacobsen et al. [9] evaluated the acute or systemic toxicity of heavy metals in tattoo inks in the human body. It is well known that nickel and chromium can cause sensitization issues, but the opinion of the authors is that these elements seem to have less impact on sensitization issues based on allergy test results. Sensitization can also be caused by aromatic amines. Additionally, other heavy metals, like aluminum, can cause granulomas, and barium impacts the cardiovascular system.

Beside the assessment of pigments and their well-known impurities, it is also important to consider that almost every pigment manufacturer uses 
surface treatments in order to improve the dispersibility or achieve other specific properties of pigments [10]. Inorganic treatments (precipitation of aluminum silicates) of titanium dioxide, for example, can also decrease the photoactivity of the pigment, which is important for tattoo pigments because this reactivity is suspected to induce skin reactions after sun exposure. Another possibility for modifying the surface of pigments is to use organic compounds and to achieve precipitation by spraying combined with intensive milling. Typical compounds for organic surface treatments are polyethylenoxide, Tinuvin ${ }^{\circledR}$ 1130, dioctylphtalate, 3-isobutoxypropylamine or polydimethylsiloxane. Most tattoo ink producers don't know about the surface treatments of their pigments because pigment manufacturers are often not cooperative in exchanging this information. In conclusion, no ink producer is able to evaluate whether there are any potentially harmful impurities in their pigments, and the bioavailability of these coatings during long-term stay in the dermis and their contact with human fluids is unknown. It is possible that these impurities can cause serious reactions, like allergies or granulomas [9]. Toxicity studies of pigments in tattoo inks should consider the pure pigment itself as well as the impurities in the pigments and coatings. However, pure pigments are currently unavailable and are only achievable with high effort and cost [2].

\section{Quality Control of Pigments in the Manufacturing of Tattoo Inks}

Because pigments are produced for different applications (table 1), a tattoo ink manufacturer can't act on the assumption that the purchased pigment fulfills all limits prescribed in ResAP(2008) (table 2). Therefore, every new batch of pigment has to go through strict quality controls.

Almost every ink producer does not have the capacity to perform quality control analysis in- house, so contract analysis is common in this industry. For the determination of aromatic amines, heavy metals and PAHs, the pigment sample is extracted in a buffered solution of $0.1 \mathrm{HCl}$ for $2 \mathrm{~h}$, like is prescribed for the analysis of impurities in textiles [2]. Hence, only extractable impurities can be determined. Subsequently, aromatic amines and PAHs can be determined using gas chromatography-mass spectrometry or liquid chromatography-mass spectrometry, and heavy metals can be determined using inductively coupled plasma-mass spectrometry. Microwave extraction in strong acids is not carried out because this simulates the complete destruction of the pigment, which usually does not happen in the skin. Laser treatment can cleave the pigment into smaller particles, which can release a higher amount of impurities. However, microwave extraction is not comparable to laser treatment because it completely solubilizes the pigment, which doesn't happen during laser treatment. In order to evaluate the safety of pigments according to the impurities, it might be necessary to have two different validated sample preparation methods: (1) simulation of their long-term stay in the bodily fluid of the dermis and (2) simulation of cleavage due to laser removal or ultraviolet exposure. This could help to evaluate the safety of pigments and make the maintenance of their safety during production easier.

\section{Conclusion}

Since the EU Resolution on tattoo inks was released, the safety of these products has increased measurably due to the improved quality control of pigment raw materials in ink production and the defined impurity limits that manufacturers are able to refer to. This can be demonstrated by comparing the randomized tests of tattoo inks in Switzerland before and after the adoption of this resolution [8]. However, there are still several tattoo inks on the market that contain forbidden 
pigments or high levels of impurities. In the past 2 years, the industry has faced problems due to differences between their methods of quality control and those of the authorities. These problems were caused by missing descriptions of the methods that should be used to quantify the impurities in tattoo pigments. High-performance pigments are mostly used in tattoo inks and are very stable and chemically inert. It can be assumed that specific skin reactions after tattooing can often be the result of harmful impurities. However, the needles of tattoo devices should also be investigated because they could be a source of harmful substances, nonsterile particles or microbiological contamination, thus potentially causing serious skin reactions. The development of standardized, validated and well-adapted methods for this application has to be part of prospective efforts. In addition to this, it seems to be important to consider other harmful substances that can be present due to special pigment coatings. Most pigments that are used in tattoo inks were basically developed for other applications, like automotive coatings or plastics, and these pigments are often surface treated in this industry. Only a few pigments that are cosmetic grade are available, but none of these pigments can be purchased in pharmaceutical grade. Even a pharmaceutical-grade pigment might not be sufficient, as these pigments are not intended to be present in the skin and lymph nodes for decades. This underlines that the safety assessment of tattoo pigments has to take into account that the raw materials for these products are often technical grade. Unfortunately, this won't change in the future because tattoo inks belong to a niche market, and no pigment producer will concentrate on this business because it is not profitable enough. Concerning legislation, it might be appropriate that the first regulative approaches are based on those of cosmetics because this would be an improvement to the market, and because cosmetics and tattooing seem to be related applications. But in fact (nearly) none of these raw materials have been tested for intradermal applications and long-term exposure in the human body. Therefore, completely different risk assessments and different approaches are needed to determine their safety for that special kind of use.

\section{References}

1 Lehner K: Analysis of Black Tattoo Inks; dissertation, University of Regensburg, Regensburg, Germany, 2012.

2 BFR - German Federal Institute for Risk Assessment: Anforderungen für eine Sicherheitsbewertung von Tätowiermitteln, 2009.

3 Engel E: Tattoo Pigments in Skin; dissertation, University of Regensburg, Regensburg, Germany, 2007, pp 27-30.

4 Council of Europe, Committee of Ministers: Resolution ResAP(2008)1 on requirements and criteria for the safety of tattoos and permanent make-up. Council of Europe, 2008.
5 Faulkner E, Schwartz RJ: High Performance Pigments. Weinheim, WileyVCH, 2009.

-6 Gopee NV, Cui Y, Olson G, Warbritton AR, Miller BJ, Couch LH, Wamer WG, Howard PC: Response of mouse skin to tattooing. Toxicol Appl Pharmacol. 2005;209:145-158.

7 Kürle S, Schulte KW, Homey B: Accumulation of tattoo pigment in sentinel lymph nodes. Hautarzt 2009;60:781783.
8 Hauri U: Pigments, preservatives and impurities in tattoo inks (presentation). First International Conference on Tattoo Safety, BFR-Symposium, Berlin, June 2013.

9 Jacobsen E, et al: Chemical Substances in Tattoo Ink. Danmark, Miljøstyrelsen, 2012.

10 Winkler J: Dispergieren von Pigmenten und Füllstoffen, Farbe und Lack ed. Hannover, Vincentz Network, 2010.

11 Cuyper C, Pérez-Cotapos M-L: Dermatologic Complications with Body Art. Berlin, Springer, 2010.

Dr. Henrik Petersen

MT.DERM GmbH

Gustav-Krone-Strasse 3

DE-14167 Berlin (Germany)

E-Mail h.petersen@mtderm.de 